\title{
Remodeling of the radial artery anastomosed to the internal thoracic artery as a composite straight graft
}

Shinya Fukui, MD, Hirotsugu Fukuda, MD, PhD, Koichi Toda, MD, PhD, Masao Yoshitatsu, MD, PhD, Toshihiro Funatsu, MD, PhD, Takefumi Masai, MD, PhD, and Yuji Miyamoto, MD, PhD

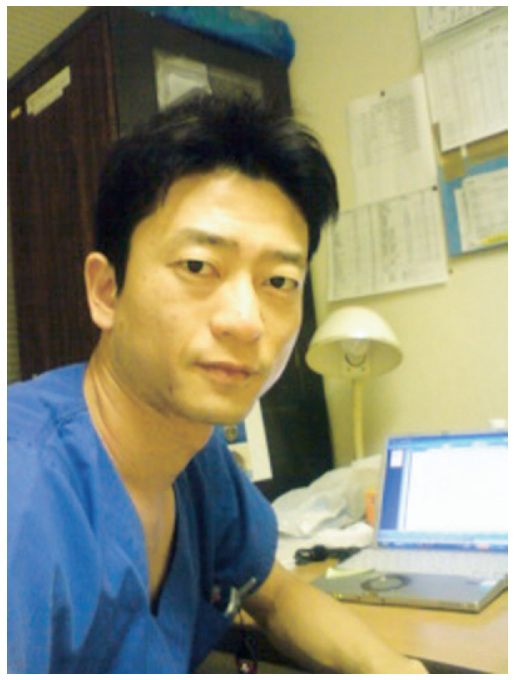

Dr Fukui

Objective: The internal thoracic artery remodels its diameter in response to flow requirements. The purpose of this study was to elucidate the remodeling of the radial artery as a composite straight graft with the internal thoracic artery.

Methods: We studied 39 patients who underwent coronary artery bypass grafting. Nineteen patients received composite straight radial and internal thoracic artery grafts, and 20 received saphenous vein grafts as aortocoronary conduits. All the grafts were sequentially anastomosed to native coronary arteries. We measured the diameters of the internal thoracic and radial arteries before surgical intervention and 3 weeks and 1 year after surgical intervention and the differences in diameter of the radial artery and saphenous vein grafts before the first and second anastomoses with native coronary arteries.

Results: The radial arteries were significantly larger in diameter than those of the internal thoracic arteries before surgical intervention $(3.54 \pm 0.46$ vs $2.31 \pm 0.40$ $\mathrm{mm}, P<.0001$ ), but there was no significant difference 3 weeks after surgical intervention $(2.19 \pm 0.49$ vs $2.15 \pm 0.45 \mathrm{~mm})$. The mean diameters of the radial and internal thoracic arteries remained almost the same 1 year after surgical intervention $(2.22 \pm 0.49$ and $2.32 \pm 0.79 \mathrm{~mm})$. The diameters of the radial artery grafts were significantly reduced after the first anastomosis $(P<.01)$, but those of the saphenous vein grafts were unchanged.

Conclusion: These results suggest that a composite straight radial and internal thoracic artery graft without a change in shear stress behaves like an extended arterial graft, with remodeling and vasoreactive capacity.

From the Division of Cardiovascular Surgery, Sakurabashi-Watanabe Hospital, Osaka, Japan.

Received for publication Jan 19, 2007; revisions received July 20, 2007; accepted for publication July 26, 2007.

Address for reprints: Shinya Fukui, MD, Division of Cardiovascular Surgery, Department of Surgery, Osaka University Graduate School of Medicine (E1), 2-2, Yamada-oka, Suita City, Osaka, 565-0871, Japan (E-mail: fukui0104@yahoo.co.jp).

J Thorac Cardiovasc Surg 2007;134:1136-42 $0022-5223 / \$ 32.00$

Copyright $\odot 2007$ by The American Association for Thoracic Surgery

doi:10.1016/j.jtcvs.2007.07.024
$\mathrm{T}$ he potential advantages of arterial conduits compared with those of saphenous vein grafts (SVGs) in coronary artery bypass grafting (CABG) have resulted in their increasing use, with the aim of achieving complete myocardial revascularization. The gold standard for arterial conduits is considered to be the internal thoracic artery (ITA), followed by the radial artery (RA). The RA was introduced as an alternative graft for myocardial revascularization in the early 1970s. ${ }^{1}$ However, its use was abandoned because of its poor patency. Twenty years later, Acar and colleagues ${ }^{2}$ reported that the RA was an excellent conduit when managed pharmacologically. Good patency of RA grafts was reported, ${ }^{3}$ and, since then, the RA has been used extensively as an aortocoronary conduit or as a composite graft with a pedicled ITA. ${ }^{4,5}$ It has been possible to achieve multiple revascularization by combining the RA with 1 or both ITAs as composite grafts. ${ }^{6,7}$ We began to use the RA as a conduit for myocardial revascularization in 1998 and started to use it as a composite straight graft with a pedicled ITA in 2000. Although postoperative changes of the ITA and RA have been well analyzed previously, ${ }^{8,9}$ change in the diameter of the RA anastomosed to the ITA as a composite straight 


$$
\begin{aligned}
& \text { Abbreviations and Acronyms } \\
& \begin{aligned}
\text { CABG } & =\text { coronary artery bypass grafting } \\
\text { ITA } & =\text { internal thoracic artery } \\
\text { NO } & =\text { nitric oxide } \\
\text { RA } & =\text { radial artery } \\
\text { RAD } & =\text { diameter of the radial artery } \\
\text { RITA } & =\text { right internal thoracic artery } \\
\text { SVG } & =\text { saphenous vein graft } \\
\text { SVGD } & =\text { diameter of the saphenous vein graft }
\end{aligned}
\end{aligned}
$$

graft has not been reported. In this article the remodeling and vasoreactive capacity of the RA used as a composite straight graft with the ITA is reviewed.

The two main objectives of this study were (1) to elucidate the remodeling capacity of the RA anastomosed to the ITA as a composite straight graft and (2) to compare the vasoreactive capacity of the RA with that of the SVG.

\section{Materials and Methods Patient Population}

Between June 2000 and June 2002, 116 patients underwent CABG at our institution. All patients signed informed consent forms before the operation. In 19 patients RAs were used as composite straight grafts with ITAs and sequentially anastomosed. We chose 20 patients in whom SVGs were used as aortocoronary conduits and sequentially anastomosed from those who had CABGs in the same period. The 19 with composite straight grafts and the 20 with sequential SVGs were all patients with sequential grafts. Other patients had stenoses of diagonal or obtuse marginal arteries that were singly grafted by free RAs or SVGs with proximal anastomoses on the aorta and were excluded from our cohorts. The preoperative characteristics of the patients are shown in Table 1. Significantly younger patients had composite straight grafts because such patients should be treated with arterial grafts that have good long-term patency. The proportion of diabetes was significantly higher in the SVG group than that in the composite graft group. All patients had coronary angiography 3 weeks after surgical intervention to evaluate the patency of the grafts. Only 10 patients with composite straight grafts had follow-up angiography 1 year after surgical intervention. Other patients declined a second angiogram because they had no symptoms. All patients with composite straight grafts were given intravenous calcium-channel blockers during the operation, followed by long-term oral administration for at least 6 months. For this, $0.5 \mu \mathrm{g} \cdot \mathrm{kg}^{-1} \cdot \mathrm{min}^{-1}$ diltiazem was continuously injected into all patients with composite grafts during the operation and continued until they could take $200 \mathrm{mg} / \mathrm{d}$ oral diltiazem. Medication was continued for at least 6 months as long as the patients did not have side effects, such as bradycardia and hypotension.

\section{Surgical Technique}

The RA was harvested from its origin to the wrist crease by a single surgeon using the extrafascial technique. Papaverine diluted with saline was sometimes sprayed on the artery during harvesting
TABLE 1. Preoperative clinical characteristics of patients

\begin{tabular}{lccc}
\hline & $\begin{array}{c}\text { Composite } \\
\text { straight grafts }\end{array}$ & SVGs & $\boldsymbol{P}$ value \\
\hline Male/female sex & $18 / 1$ & $17 / 3$ & .61 \\
Mean age (y) & $62.0 \pm 6.7$ & $68.9 \pm 5.9$ & .0019 \\
Preoperative findings & & & \\
$\quad$ Coronary artery disease & & & \\
$\quad$ Single-vessel disease & 0 & 0 & -50 \\
$\quad$ Double-vessel disease & 5 & 8 & .50 \\
$\quad$ Triple-vessel disease & 14 & 12 & .50 \\
Risk factors & & & \\
$\quad$ Diabetes & 3 & 11 & .02 \\
$\quad$ Smoking & 12 & 14 & .74 \\
Hyperlipidemia & 1 & 3 & .61 \\
Hypertension & 8 & 10 & .75 \\
Unstable angina & 4 & 3 & .69 \\
Previous AMI & 10 & 13 & .52 \\
\hline
\end{tabular}

SVGs, Saphenous vein grafts; $A M I$, acute myocardial infarction.

to avoid spasm. After harvesting, RAs were flushed out with heparin and then soaked in papaverine until use. All the RAs were harvested as pedicled grafts and anastomosed to pedicled right internal thoracic arteries (RITAs) as composite straight grafts. For 11 patients with stenoses of posterodescending and posterolateral arteries, the composite straight grafts were directed along the right side (Figure 1, A). For the other 8 patients with obtuse marginal and posterolateral arteries or with stenoses of diagonal and obtuse marginal or posterolateral arteries, composite straight grafts were directed over the aorta (Figure 1, $B$ and $C$ ). In the case of sequential anastomosed SVGs, the operative procedures are shown in Figure 1, $D$ through $G$. The distal sites of anastomosis are shown in Table 2. All patients except one with the SVG sequentially anastomosed to the left anterior descending and obtuse marginal artery had left ITA to left anterior descending artery grafts. All CABGs were performed during cardioplegic arrest with cardiopulmonary bypass.

\section{Measurement of ITAs, RAs, and SVGs}

The diameters of the preoperative and postoperative ITAs were measured on an angiogram about $10 \mathrm{~mm}$ proximal to the distal end and $10 \mathrm{~mm}$ proximal to the anastomotic site with the RA (Figure $2, A)$. We did not use ITAs diffusely narrowed by arteriosclerosis or ITAs with a diameter of less than $1.8 \mathrm{~mm}$ on preoperative angiography. The diameters of the preoperative RAs were measured $15 \mathrm{~mm}$ distal to the proximal end by means of duplex scanning (SONOS 5500, Hewlett-Packard) with a 7-MHz linear transducer, and those of the postoperative RAs were measured 10 $\mathrm{mm}$ distal to the anastomotic site with the RITA (Figure 2, A). We did not use RAs with a diameter of less than $2.5 \mathrm{~mm}$ on preoperative examination.

The diameters of the RAs and SVGs were measured about 10 mm proximal to the first $\left(\mathrm{RAD}_{1}\right.$ and $\left.\mathrm{SVGD}_{1}\right)$ and second $\left(\mathrm{RAD}_{2}\right.$ and $\mathrm{SVGD}_{2}$ ) anastomotic sites of the sequential bypass grafts to compare the vasoreactive capacity of RAs with that of SVGs (Figure 2). These angiographic diameters were calculated as references to catheter sizes (Centricity CA1000, GE Healthcare). 
A

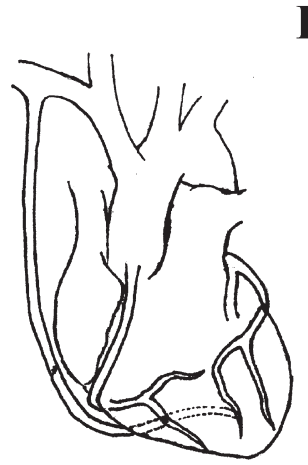

D

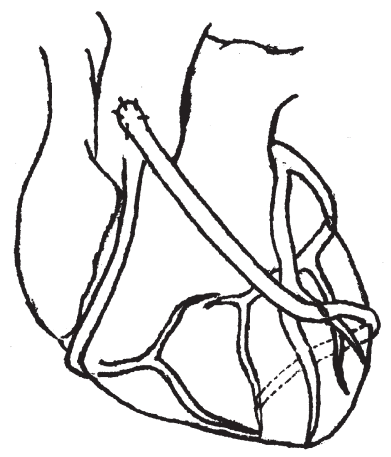

F

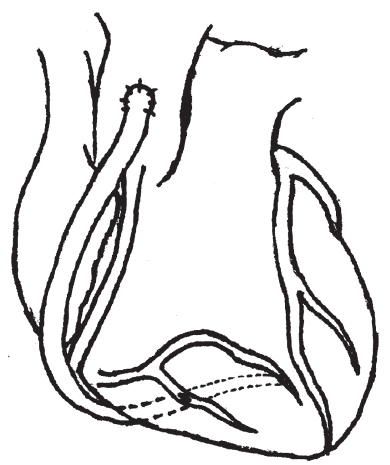

C

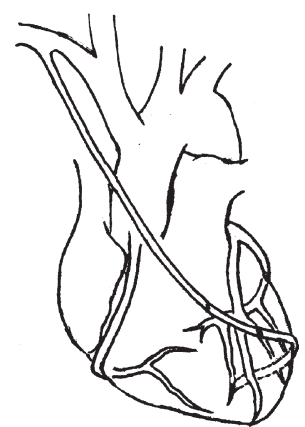

E

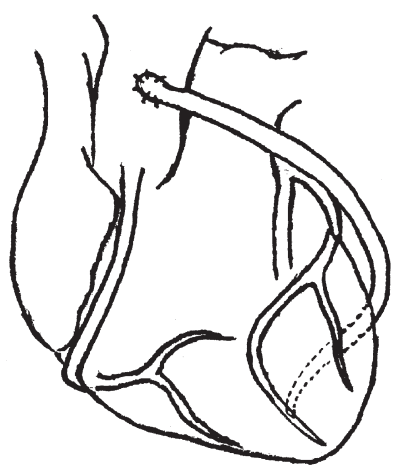

G

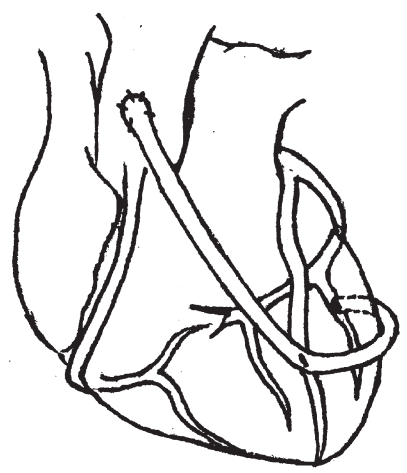

Figure 1. Operative procedure. All patients except one (G) with saphenous vein grafts (SVGs) sequentially anastomosed to the left anterior descending and obtuse marginal artery had left internal thoracic artery to left anterior descending artery grafts. A, Composite straight grafts are directed along the right side in patients with stenoses of posterodescending and posterolateral arteries ( $n=11$ ). B and C, Composite straight grafts are directed over the aorta in patients with stenoses of the posterolateral and obtuse marginal arteries or with diagonal and posterolateral or obtuse marginal arteries $(\mathbf{n}=$ 8). D, Sequential anastomosed SVGs in patients with stenoses of the diagonal and posterolateral arteries ( $n=4)$. $E$, Sequential anastomosed SVGs in patients with stenoses of the obtuse marginal and posterolateral arteries and with stenoses of the 2 posterolateral arteries ( $n=3$ and 1). F, Sequential anastomosed SVGs in patients with stenoses of the posterodescending and posterolateral arteries $(n=11)$. G, Sequential anastomosed SVGs in patients with stenoses of the left anterior descending and obtuse marginal arteries ( $n=1)$.

\section{Statistical Analysis}

All data were expressed as means \pm standard deviation. To assess significance within the group or between 2 groups, a paired or unpaired Student $t$ test was used to verify the changes by using StatView 5.0 software (Abacus Concept).

\section{Results}

Nineteen patients with composite straight grafts and 20 patients with SVGs were studied 3 weeks after surgical intervention with angiography. There was no in-hospital mortality or perioperative myocardial infarction. All the grafts were patent on angiography. Ten of those who had composite straight grafts underwent follow-up angiography 1 year after surgical intervention. One RA that was sequentially anastomosed to the posterior descending and postero- lateral branches of the right coronary artery with a stenosis of $75 \%$ showed diffuse narrowing.

\section{Changes in Diameters of RAs and ITAs}

The mean diameter of the RAs was much greater than that of the RITAs before surgical intervention $(3.54 \pm 0.46$ vs $2.31 \pm 0.40 \mathrm{~mm}, P<.0001$; Figure $3, B)$. The mean diameters of the RAs and ITAs 3 weeks after surgical intervention were $2.19 \pm 0.49$ and $2.15 \pm 0.45 \mathrm{~mm}$, respectively (Figure 3,B). Differences in the preoperative mean diameters of the RAs and ITAs disappeared 3 weeks after surgical intervention (Figure 3, $A$ and $B$ ). Furthermore, the RAs and ITAs both tended to have slightly increased diameters 1 year after surgical intervention, although this 
TABLE 2. Operative details

\begin{tabular}{lccc}
\hline Variable & $\begin{array}{c}\text { Composite straight } \\
\text { grafts }(\mathbf{n}=\mathbf{1 9})\end{array}$ & $\begin{array}{c}\text { SVGs } \\
(\mathbf{n}=\mathbf{2 0})\end{array}$ & $\begin{array}{c}\boldsymbol{P} \\
\text { value }\end{array}$ \\
\hline Total no. of anastomoses & 63 & 73 & \\
$\quad$ Anastomoses per patient & $3.3 \pm 0.7$ & $3.7 \pm 0.7$ & .15 \\
Sequential grafting & $100 \%$ & $100 \%$ & \\
No. of RA or SVG & 38 & 40 & \\
$\quad$ anastomoses & & & \\
Target location & & & \\
LAD & 0 & 1 & .33 \\
Dx & 3 & 4 & .74 \\
OM & 4 & 4 & .94 \\
PL & 19 & 20 & - \\
PD & 12 & 11 & .69
\end{tabular}

$S V G s$, Saphenous vein grafts; $R A$, radial artery; $L A D$, left anterior descending artery; $D x$, diagonal artery; $O M$, obtuse marginal artery; $P D$, posterodescending artery; $P L$, posterolateral artery.

was not significant $(2.22 \pm 0.49$ and $2.32 \pm 0.77 \mathrm{~mm}$, respectively; Figure 3, $B$ ).

\section{Change in Ratio of ITA to RA Diameter}

The ratio of ITA to RA diameter was significantly increased 3 weeks after surgical intervention (from $0.67 \pm 0.10$ to $0.99 \pm 0.17, P<.0001 ;$ Figure $3, C)$. The ratio 1 year after surgical intervention was unchanged from that seen 3 weeks after surgical intervention $(1.0 \pm 0.19)$.

\section{Changes in Diameters of Sequentially Anastomosed RAs and SVGs}

The mean $\mathrm{RAD}_{1}$ was significantly greater than the mean $\mathrm{RAD}_{2} 3$ weeks after surgical intervention $(2.11 \pm 0.43$ vs $1.67 \pm 0.43 \mathrm{~mm}, P<.01$; Figure $4, A)$. The ratio of $\mathrm{RAD}_{2}$ to $\mathrm{RAD}_{1}$ was $0.81 \pm 0.12$. One year after surgical intervention, the mean $R A D_{1}$ was still significantly greater than the mean $\mathrm{RAD}_{2}(2.34 \pm 0.45$ vs $1.69 \pm 0.57 \mathrm{~mm}, P<.05)$, and they were the same as those 3 weeks after surgical intervention (Figure 4, B). The mean $\mathrm{SVGD}_{1}$ was not significantly different from the mean $\mathrm{SVGD}_{2} 3$ weeks after surgical intervention $(2.92 \pm 0.61$ vs $2.91 \pm 0.68 \mathrm{~mm}$; Figures $3, A$, and $4, C$ ).

\section{Discussion}

Since the RA was reported to have good patency as an arterial conduit for $\mathrm{CABG},{ }^{2}$ it has been widely used as a composite graft with the ITA. Although the RA has been analyzed in detail before, ${ }^{3-6}$ its remodeling capacity and vasoreactivity when used as a composite straight graft with the ITA have not been reported. Here we elucidated the remodeling capacity of the RA used as a composite straight graft and its vasoreactive capacity when sequentially anastomosed, with measurements taken 3 weeks and 1 year after surgical intervention.
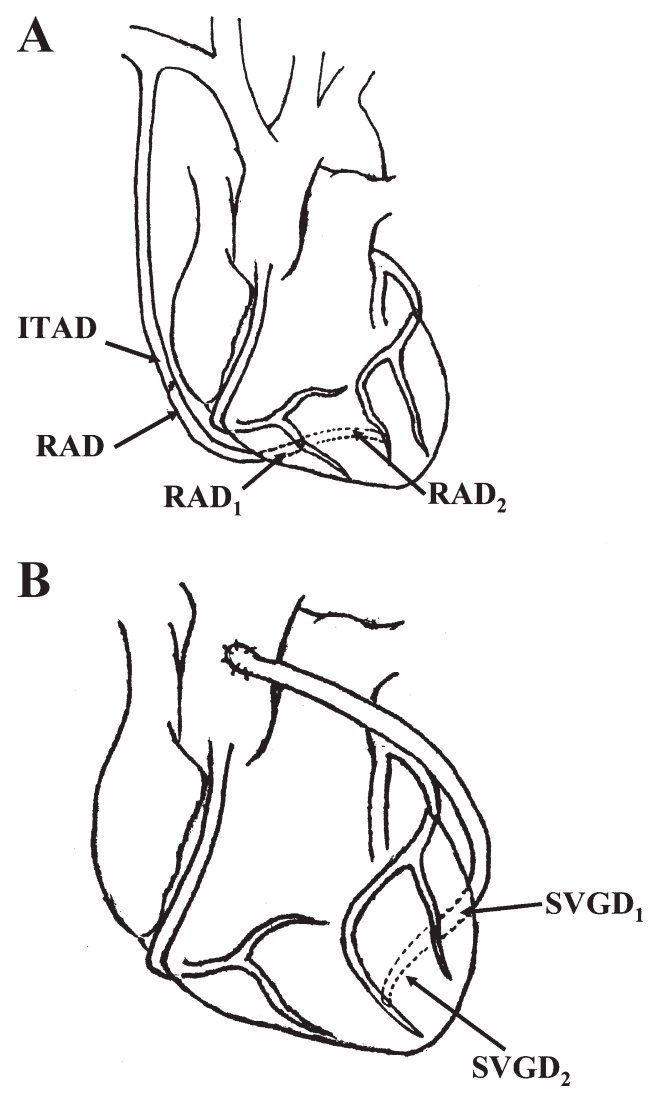

Figure 2. Sites of preoperative and postoperative measurements of each graft. A, Sites of postoperative angiographic measurements of the radial artery and internal thoracic artery. The diameters of the internal thoracic artery and radial artery were measured $10 \mathrm{~mm}$ proximal and $10 \mathrm{~mm}$ distal to the anastomosis, respectively. $R A D_{1}$ and $R A D_{2}$ values were measured $10 \mathrm{~mm}$ proximal to the anastomoses with native coronary arteries. ITAD, Diameter of the internal thoracic artery; $R A D$, diameter of the radial artery; $R A D_{1}$, diameter of the radial artery before the first anastomosis; $R A D_{2}$, diameter of the radial artery before the second anastomosis. B, Sites of postoperative angiographic measurements of the saphenous vein grafts sequentially anastomosed. SVGD 1 and $S_{1}$ GD $_{2}$ values were measured $10 \mathrm{~mm}$ proximal to the anastomoses with native coronary arteries. $S V G D_{1}$, Diameter of the saphenous vein graft before the first anastomosis; $S V G D_{2}$, diameter of the saphenous vein graft before the second anastomosis.

First, we showed that the diameter of the RA used as a composite straight graft reduced to close to the diameter of the ITA at 3 weeks after surgical intervention and then gradually increased with time, together with the diameter of the ITA (Figure 3). These findings are very important with regard to preventing stenosis and obstruction at the anastomosis.

Flowing blood creates 2 principal vectors in a vessel. ${ }^{10}$ One is perpendicular to the wall and is determined by the 
A
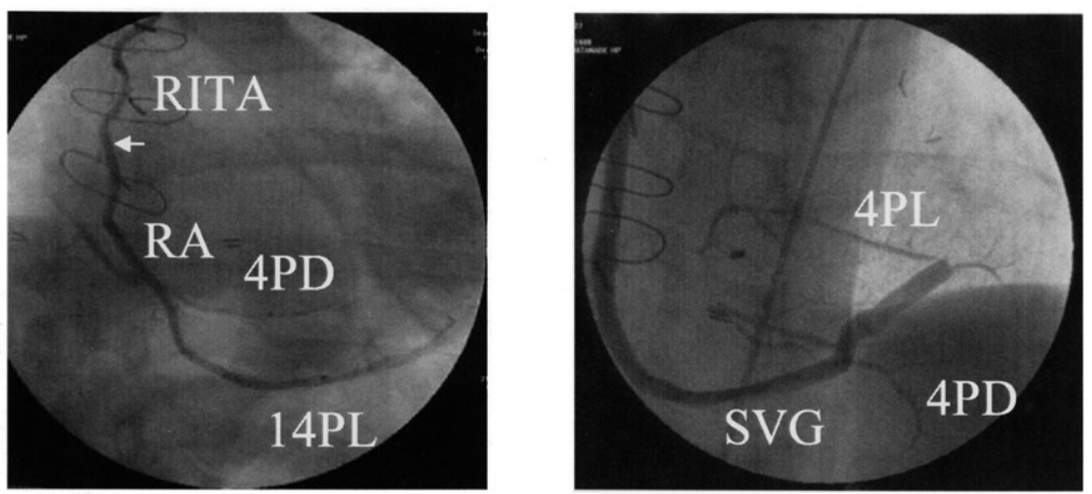

B

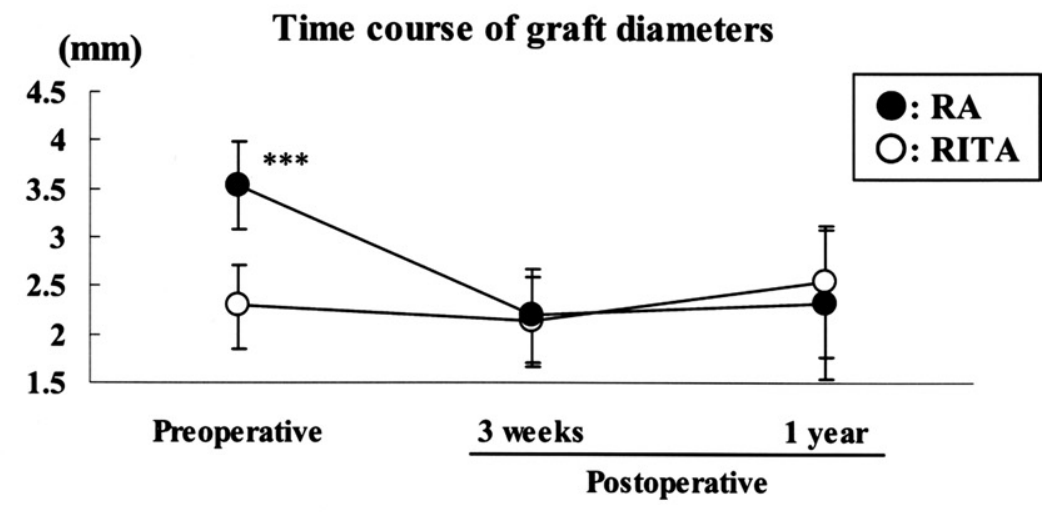

C

The ratio of ITA to RA

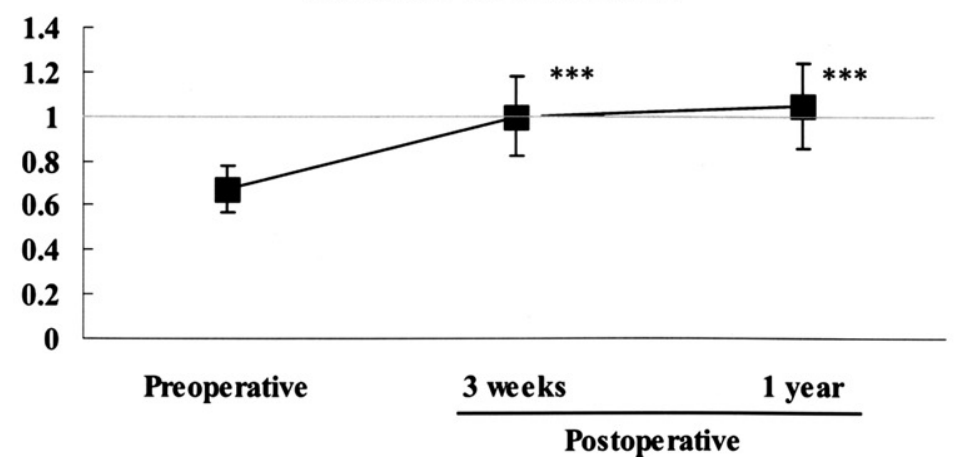

Figure 3. A, Angiogram of composite straight grafts and saphenous vein grafts (SVGs) 3 weeks after surgical intervention. Left, The difference in diameters between the radial arteries and right internal thoracic arteries before surgical intervention had disappeared 3 weeks after surgical intervention. Right, Sequentially anastomosed saphenous vein graft 3 weeks after surgical intervention. The arrow indicates the anastomosis of the radial artery to the right internal thoracic artery. RITA, Right internal thoracic artery; $R A$, radial artery; $P D$, posterior descending branch; $P L$, posterolateral branch; SVG, saphenous vein graft. $B$, Change in the diameters of the grafts with time. The preoperative diameters of the radial arteries were significantly different from those of the right internal thoracic arteries. The diameters of the radial arteries and internal thoracic arteries were almost the same 3 weeks and 1 year after surgical intervention. The specific comparisons also indicate significance. $R \boldsymbol{A}$, Radial artery; RITA, right internal thoracic artery. ${ }^{* * *}$ Radial artery vs right internal thoracic artery: $P<.0001$. C, Change in the ratio of the internal thoracic artery to the radial artery diameter with time. The ratio of internal thoracic artery to radial artery diameter increased to almost 1 at 3 weeks and 1 year after surgical intervention. ITA, Internal thoracic artery; $\boldsymbol{R A}$, radial artery. ${ }^{* *} \boldsymbol{P}<$ .001 compared with the preoperative ratio. blood pressure. The other is parallel to the wall and creates a frictional force, shear stress, at the endothelial surface. Shear stress is related to the flow velocity and is influenced by curvatures in the vessel wall, bifurcations and branches, where flow velocity decreases and a recirculation zone forms. Shear stress values in the recirculation zone are around 1 order of magnitude less than in the entrance zone. ${ }^{11}$ Low shear stress induces the attachment of endothelial cells and leukocytes, resulting in thrombus, intimal hyperplasia, and stenosis or occlusion. If the postoperative diameter of the RA did not reduce to match that of the ITA, a recirculation zone would occur at the anastomosis, and shear stress would reduce as a result of the decrease in flow velocity, which would result in graft stenosis or occlusion.

Second, we showed that the RA decreased in diameter between the first and second anastomoses (Figure 4, $A$ and $B$ ), but the SVG did not alter its diameter (Figure 4, $C)$. If these results could be referred to the original diameters of the distal and proximal sites of RAs, the mean diameters of the RAs at the anastomotic site with the ITAs and the RAs before the first anastomoses with native 
A

\section{3 weeks after surgey}

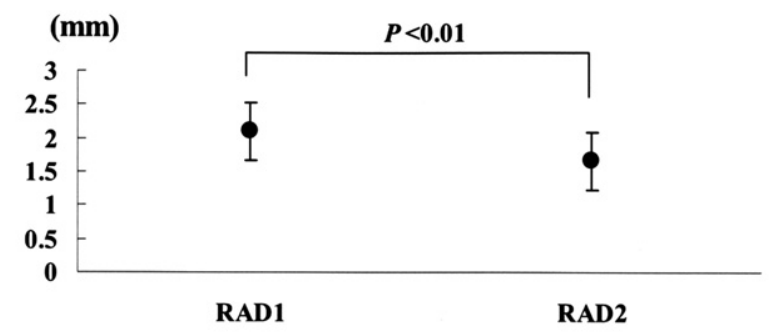

B

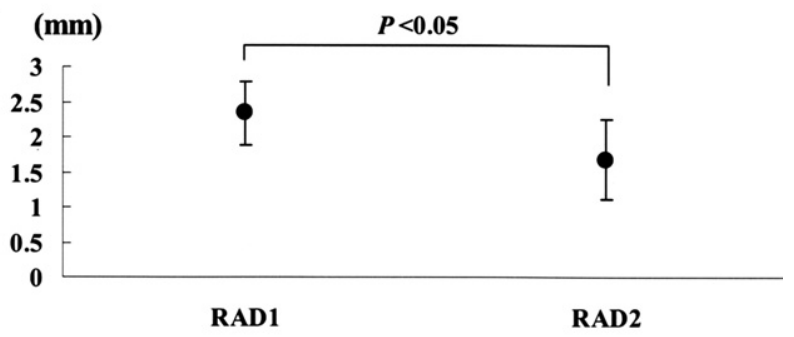

C

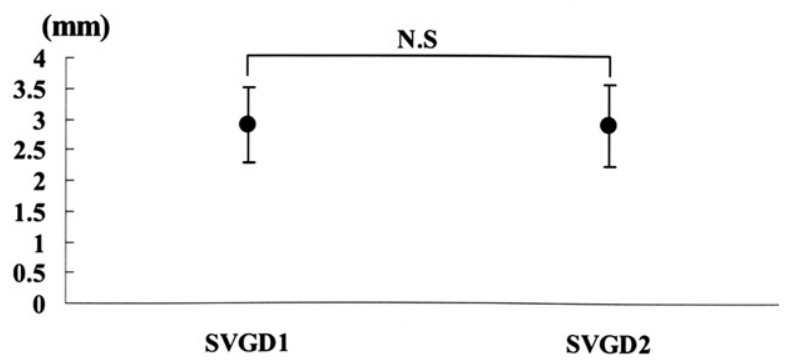

Figure 4. A, Change in the diameters of the radial arteries (RA) before the first and second anastomoses 3 weeks after surgical intervention. The radial arteries had changed their diameters before the first and second anastomoses with native coronary arteries 3 weeks after surgical intervention. $R A D_{1}$, Diameter of the radial artery before the first anastomosis; $R A D_{2}$, diameter of the radial artery before the second anastomosis. $B$, Change in the diameters of the radial arteries before the first and second anastomoses 1 year after surgical intervention. The radial arteries had changed their diameters before the first and the second anastomoses with native coronary arteries 1 year after surgical intervention. $R A D_{1}$, Diameter of the radial artery before the first anastomosis; $R A D_{2}$, diameter of the radial artery before the second anastomosis. C, Change in the diameters of the saphenous vein grafts before the first and second anastomoses 3 weeks after surgical intervention. The saphenous vein grafts had not changed their diameters before the first and second anastomoses with the native coronary arteries 3 weeks after surgical intervention. $S V G D_{1}$, Diameter of the saphenous vein graft before the first anastomosis; $S V G D_{2}$, diameter of the saphenous vein graft before the second anastomosis. coronary arteries would become different. However, in our study mean RAD and $\mathrm{RAD}_{1}$ values were almost the same $(2.19 \pm 0.49$ and $2.11 \pm 0.43 \mathrm{~mm}$, respectively). Therefore, we believe that these results were due to the vasoreactive capacity of the RA. This indicates that the RA adjusts its caliber to suit the flow requirement placed on it, which eventually normalizes shear stress at the endothelial interface and allows the conduit to deliver an appropriate flow to the subserved vascular bed. The endothelium plays a crucial role in responding to the change in shear stress. Increasing flow by means of pacing results in increased diameter, and reducing flow by means of branch ligation results in reduced diameter. $^{12,13}$ The in situ RA used as an arteriovenous fistula has a 6-fold increase in blood flow, a 1.4-fold increase in internal diameter, and a constant shear stress. ${ }^{14}$ $>$ It is apparent that the RA can adjust its diameter to the flow requirement anastomosed to it and maintain a constant shear stress. The responses are dependent on endothelium, and removal of the endothelium prevents these alterations. ${ }^{15}$ Flow-sensitive endothelial potassium-channel activity has been linked to release of an endogenous nitric oxide (NO) in arterial rings. ${ }^{16}$ This initiates vasodilation and remodeling if the flow increase persists. Endothelial release of NO is the principal mediator of shear stress-induced vasoregulation. Endothelial NO production and vasoreactivity are greater in the RA than they are in the SVG. ${ }^{17}$ The RA is reported to maintain its endothelial function and remodeling capacity 5 years after implantation when anastomosed to the aorta. $^{18}$

This study has the following limitations. First, each cohort had a small population. Therefore, both cohorts had significant differences in their proportions of diabetes. Second, long-term function of the RA as a composite graft has not been evaluated. Therefore, we need ongoing observation of the RA anastomosed to the ITA as a composite straight graft. Third, we only elucidated the anatomic change in the RA used as a composite graft before and after surgical intervention. We should also examine physiologic and pharmacologic changes in the RA used as a composite graft. For example, physiologic changes could be confirmed by introducing a vasoconstrictor or vasodilator through a catheter.

In conclusion, the RA is an excellent arterial graft for CABG, not only as an aortocoronary conduit but also as a composite graft with the ITA. These results suggest that the ITA-RA composite straight graft without a change in shear stress behaves like an extended arterial graft, with remodeling and vasoreactive capacity.

\section{References}

1. Carpentier A, Guermonpres JL, Deloche A, Frechette C, Dubost C. The aorta-to-coronary radial artery bypass graft: a technique avoiding pathological changes in grafts. Ann Thorac Surg. 1973;16:111-21. 
2. Acar C, Jebara VA, Portoghese M, Beyssen B, Pagny JY, Grare P, et al. Revival of the radial artery for coronary artery bypass grafting. Ann Thorac Surg. 1992;54:652-60.

3. Chen AH, Nakao T, Brodman RF, Greenberg M, Charney R, Menegus $\mathrm{M}$, et al. Early postoperative angiographic assessment of radial artery grafts used for coronary artery bypass grafting. J Thorac Cardiovasc Surg. 1996;111:1208-12.

4. Weinschelbaum EE, Gabe ED, Macchia A, Sminno R, Suarez LD. Total myocardial revascularization with arterial conduits: radial artery combined with internal thoracic arteries. J Thorac Cardiovasc Surg. 1997;114:911-6.

5. Calafiore AM, Giammarc GD, Teodori G, D'Annunzio E, Vitolla G, Fino C, et al. Radial artery and inferior epigastric artery in composite grafts: improved midterm angiographic results. Ann Thorac Surg. 1995;60:517-24

6. Nakamura Y, Kobayashi J, Tagusari O, Bando K, Niwaya K, Nakajima $\mathrm{H}$, et al. Early results of complete off-pump coronary revascularization using left internal thoracic artery with composite radial artery. Jpn J Thorac Cardiovasc Surg. 2003;51:10-5.

7. Sakaguchi G, Tadamura E, Ohnaka M, Tambara K, Nishimura K, Komeda M. Composite arterial Y graft has less coronary flow reserve than independent grafts. Ann Thorac Surg. 2002;74:493-6.

8. Yoshitatsu M, Miyamoto Y, Mitsuno M, Toda K, Yoshikawa M, Fukui $\mathrm{S}$, et al. Changes in left anterior descending coronary artery flow profiles after coronary artery bypass grafting examined by means of transthoracic Doppler echocardiography. J Thorac Cardiovasc Surg. 2003;126:1531-6.

9. Akasaka T, Yoshida K, Hozumi T, Takagi T, Kaji S, Kawamoto T, et al. Flow dynamics of angiography no-flow patent internal mammary artery grafts. J Am Coll Cardiol. 1998;31:1049-56.
10. Barner HB. Remodeling of arterial conduits in coronary grafting. Ann Thorac Surg. 2002;73:1341-5.

11. Bluestein D, Niu L, Schoephoerster RT, Dewanjee MK. Steady flow in an aneurysm model: correlation between fluid dynamics and blood platelet deposition. J Biomech Eng. 1996;118:280-6.

12. Al-Bustami MH, Amrani M, Chester AH, Ilsley CJ, Yacoub MH. In vivo early and mid-term flow-medical endothelial function of the radial artery used as a coronary bypass graft. $J$ Am Coll Cardiol. 2002;39:573-7.

13. Langille BL, Bendeck MP, Keeley FW. Adaptations of carotid arteries of young and mature rabbits to reduce carotid blood flow. Am J Physiol Heart Circ Physiol. 1989;256:H931-9.

14. Girerd X, London G, Boutouryrie P, Mourad JJ, Safar M, Laurent S. Remodeling of the radial artery in response to a chronic increase in shear stress. Hypertension. 1996;27(suppl):799-803.

15. Langelle BL, O'Donnell F. Reductions in arterial diameter produced by chronic decreases in blood flow are endothelium-dependent. Science. 1986;231:405-7.

16. Olesen SP, Bundgaard M. ATP-dependent closure and reactivation of inward rectifier K+ channels in endothelial cells. Circ Res. 1993;73: 492-5.

17. Shapira OM, Xu A, Aldea GS, Vita JA, Shemin RJ, Keaney JF. Enhanced nitric oxide-mediated vascular relaxation in radial artery compared with internal mammary artery or saphenous vein. Circulation. 1999;100(suppl II):II322-7.

18. Gaudino M, Glieca F, Trani C, Lupi A, Mazzari MA, Schiavoni G, et al. Midterm endothelial function and remodeling of radial artery grafts anastomosed to the aorta. J Thorac Cardiovasc Surg. 2000;120:298301. 